\title{
The lessons of Study 329: How fraud in psychiatric drug research got normalised
}

\author{
ROBERT B WHITAKER
}

David Healy, Joanna Le Noury, Julie Wood. Children of the cure: Missing data, lost lives and antidepressants. Samizdat Health Writers' Cooperative; 2020. Paperback \$ 16.95. 269 pgs, ISBN 978-1-7770565-8-2.

Study 329, which was a trial of paroxetine for depression in adolescents, is often held up as the poster child for fraud in clinical trials of psychiatric drugs. A 2001 article published in the Journal of the American Academy of Child and Adolescent Psychiatry (JAACAP) (1) told of a drug that was safe and effective for treating adolescent depression. It subsequently became known that SmithKline Beecham's own medical review team had concluded in 1998 that the drug had failed to show efficacy. Working with a ghostwriting firm, the company — which by 2001 had morphed into GlaxoSmithKline-spun the results in the published article, and hid evidence of an increased risk of suicide in the paroxetine group.

Meanwhile, the listed authors of the study, hailing from prestigious medical schools in the United States, lent their names to this ghostwriting exercise.

In Children of the cure: Missing data, lost lives and antidepressants, David Healy, Joanna Le Noury and Julie Wood painstakingly detail the entire sordid affair, including efforts to get the study retracted and to reanalyse the patient-level data. However, they do so with a larger purpose in mind. Study 329 is not presented as an aberration, but rather as emblematic of a systemic failure in modern medicine (or at least in psychiatry), which leads to prescribing practices that do great harm.

In their introduction, they make their intentions clear:

Every day of the week, many of us take a pill, it might be an antibiotic, a pill for skin or heart problems or an antidepressant. This story about ghost-writing and the hiding

Author: Robert B Whitaker (robert.b.whitaker@verizon.net), Adjunct Clinical Instructor, Lewis Katz School of Medicine, Temple University, Pennsylvania, USA; and President, Mad in America Foundation, USA.

To cite: Whitaker RB. The lessons of Study 329: How fraud in psychiatric drug research got normalised. Indian J Med Ethics. 2021 Jan-Mar; 6(1) NS: 76-78. DOI:10.20529/IJME.2020.087.

Published online on August 20, 2020.

Manuscript Editor: Sanjay A Pai.

(c) Indian Journal of Medical Ethics 2020 of clinical trial data, especially the data on what can go wrong on a pill, applies to every pill you might take. But no-one tells you that you run these risks.

With that larger theme in mind, they open their investigation of Study 329 in the manner of a detective story: A BBC television reporter, Shelley Jofre, reads the Study 329 article on a flight to the United States to attend the American Psychiatric Association annual conference, and wonders about a side effect dubbed "emotional lability". What does that mean?

With that thought hanging in the air-and the fact that the hero of their story is going to be a journalist, as opposed to a medical expert-the authors of Children of the cure detail the historical path that led up to Study 329. It is a story of how fraud and deception were normalised.

\section{The antidepressant boom: Spin made it possible}

While this history is somewhat well known, Healy and coauthors present it with great clarity, and by doing so, they make a convincing case that GlaxoSmithKline (GSK) was proceeding in the same manner as other drug companies that had popularised Selective serotonin reuptake inhibitors (SSRIs). Ghost-writing, the spinning of results, and the hiding of adverse events had become the rule, with the Food and Drug Administration (FDA) turning a blind eye to this corruption of science.

During the 1960s and 1970s, benzodiazepines were the drugs of choice for anxiety, a condition common to many. Clinical depression was "a rare disorder-several thousand times less common than it is now thought to be," the authors write. However, benzodiazepines began to fall from favour in the 1970s because of concerns that they were addictive, and pharmaceutical companies turned to "antidepressants" as a replacement.

The American Psychiatric Association paved the way for this marketing enterprise when it published the third edition of its Diagnostic and statistical manual in 1980. Freudian notions of neurotic conditions were reconceptualised as illnesses of the brain, which provided pharmaceutical companies with an opportunity to sell drugs for emotional difficulties-anxiety and mild forms of depression-that were common in the general population.

Yet, as drug companies sought to develop drugs that acted on the serotonergic system, they ran into a roadblock. 
These agents weren't particularly effective as a treatment for depression and their side effects were troublesome. But the market beckoned, and in the late 1980s, Eli Lilly, with its drug fluoxetine, provided a template for getting past the scientific barriers.

In clinical studies, fluoxetine failed to beat placebo in several trials, and was only marginally better than placebo in the positive studies that the FDA relied upon to approve the drug.

Meanwhile, case report forms told of a drug that could stir akathisia in a significant percentage of patients, which is a known risk for suicide. But that adverse effect, Healy and his co-authors write, was coded "as agitation--and as restlessness, hyperactivity, anxiety, and depression" in order to hide the suicide risk. ( $p$ 49)

Eli Lilly marketed fluoxetine as a "selective serotonin reuptake inhibitor," and the era of "biobabble" was on. The public was told that SSRIs fixed a chemical imbalance thought to cause depression, and while this notion brilliantly served commercial interests, it was devoid of any scientific merit.

The commercial success of fluoxetine provided a model for other drug companies to follow. The clinical studies of sertraline and paroxetine similarly revealed that these drugs were, at best, marginally effective, and there were hints that they increased the risk of suicide. But the trial data could be massaged, and once the FDA put its stamp of approval on the drugs, the marketing stories could begin.

"There was a lot of sharp practice involved," Healy and his coauthors write. "There was statistical juggling of trial data by all the companies, and a recording of suicide events, which went undetected by journalists and others watching what was happening. The juggling was noted by the FDA as being in breach of regulations, but the FDA did nothing about it." ( $p$ 54)

The marketing of antidepressants to adolescents was really more of the same. Prior to this time, the belief in psychiatry had always been that moodiness was an ordinary part of growing up. Clinical depression was rarely, if ever, seen in this young population. But by the early 1990s, the pharmaceutical companies were eying children and adolescents as an untapped market, and American psychiatry suddenly discovered that its past belief was mistaken. Children and adolescents could suffer from depression, and they needed help.

Eli Lilly was the first to gain regulatory approval. Two negative studies of fluoxetine in adolescents were spun into positive ones, and in 2003, the FDA approved it for paediatric use.

The trial data from two studies of paroxetine in adolescents were so dismal that GSK didn't bother to seek approval from the FDA for paediatric labeling. In a 1998 memo, the company's "Central Medical Affairs Team" concluded that both studies had failed to show efficacy. The spinning of Study 329 was done to promote off-label use.
That memo was discovered during a lawsuit and leaked to the Canadian Medical Association Journal, which published it in 2004 (2). Meanwhile, Shelley Jofre reported several stories for BBC Scotland on paroxetine and its risks, including one on Study 329.

Healy and his co-authors write:

The question for every reader is: How could a journalist with no medical training, Shelley Jofre, spot the problems that the authors and reviewers of Study 329 failed to detect? Precisely because she was not in the field, the journal's reputation and the distinction of the names on the authorship line meant nothing to her. Because statistical significance was not part of her everyday world, she wasn't hypnotized into thinking that non-significant events weren't happening. She didn't assume 'emotional lability' referred to some inconsequential change on treatment; she noticed that it was happening more on Paxil and began to ask questions. The lack of sensible answers ultimately led to the discovery of company documents conceding that Paxil didn't work and that the entire study was ghostwritten. ( $p$ 87)

\section{The mainstream averts its eyes}

The second half of Children of the cure tells of the medical establishment's response to this fraud. In a way, this is the most dispiriting part of the book. One might have hoped that this fraud would have led the medical establishment to spring into action and clean up its own house, but instead, it mostly circled the wagons.

In a National Institute of Mental Health-funded study of adolescent depression, known as TADS, the authors hid the fact that nearly all of the suicidal acts occurred in youth on fluoxetine (rather than in the placebo and cognitive behavioural therapy groups ( $p p$ 90-91) (3). Then, after the FDA issued a black box warning in 2004 that antidepressants doubled the risk of suicidal thinking and behaviour in adolescents, epidemiologist Robert Gibbons claimed that the warning had led to a drop in antidepressant usage and an increased rate of suicide in children, a "finding" that was eagerly embraced by mainstream psychiatry (4). .However, the claim blew up when close examination of actual prescription data showed there was no such correlation (5).

This was a medical establishment protecting its product, rather than engaging in any soul searching, and there was more to come. JACAAP refused to retract Study 329 and the article continued to be cited by others as evidence of paroxetine's efficacy in adolescents. When Australian psychiatrist Jon Jureidini and his colleagues sought to publish an account of their futile efforts to get the study retracted, $B M J$, which had expressed an interest in this sordid affair, decidedafter two reviews-not to publish it (pp 127-30). The article was subsequently published by a less well-known journal, Accountability in Research (6). 
A determined group of researchers-Jureidini, Healy, Le Noury, Mickey Nardo, and others-eventually gained access to patient-level data from Study 329, and their reanalysis, as could be expected, found that paroxetine had not shown efficacy "for any prespecified primary or secondary efficacy outcome" and that there were clinically significant increases in "suicidal ideation and behavior and other serious adverse events in the paroxetine group." Theirs was a paper that revealed the fraud step-by-step, and yet the $B M J$ put them through an endless review process-multiple peer reviews, a legal review, and endless emails with $B M J$ editors - that led to their having to revise their paper seven times (pp 157-87). The BMJ finally published their re-analysis in 2015, a year after their paper was first submitted (7).

The second half of Children of the cure is not an easy read. The authors go into painstaking detail over these various themes, which can exhaust the reader. But they do so with the intent of making their larger case that the medical establishment has not reformed its ways. The editor of the New England Journal of Medicine, Jeffrey Drazen, even suggested that the re-analysis of studies would produce a new breed of "research parasites" who published papers based on the work of others, thereby throwing cold water on the idea that communal access to clinical trial data could serve the scientific good (8).

Meanwhile, in spite of "30 negative RCTs" of antidepressants in adolescents, the authors write, the prescribing of these drugs to "distressed teenagers" continues, and has even increased in recent years ( $p$ 238). The harm from this practice, they argue, can be found everywhere: increased hospitalisations for self- harm, teenagers dropping dead from heart problems and suicides, and occasional acts of horrible violence by younger males put on the drugs.

The third author of Children of the cure is Julie Wood, who along with her husband Peter, helped create RxISK.org, a website that provides information about drug risks. Her bio provides what could be the closing words for this book: "Like a growing number of others, she lost a talented and beloved child to antidepressants."

\section{References}

1. Keller MB, Ryan ND, Strober M, Klein RG, Kutcher SP, Birmaher D, et al. Efficacy of paroxetine in the treatment of adolescent major depression: a randomized, controlled trial. J Am Acad Child Adolesc Psychiatry. 2001 Jul; 40(7):762-72. Doi: 10.1097/00004583-20010700000010.

2. Kondro W, Sibbald B. Drug company experts advised staff to withhold data about SSRI use in children. CMAJ. 2004 Mar 2; 170 (5):783. doi: 10.1503/cmaj.1040213

3. Hogberg G, Antonnucio DO, Healy D. Suicidal risk from TADS study was higher than it first appeared. Int J Risk Saf Med. 2015; 27(2):85-91. Doi: 10.3233/JRS-150645.

4. Gibbons RD, Hur K, Bhaumik DK, Mann JJ. The relationship between antidepressant prescription rates and rate of early adolescent suicide. Am J Psychiatry. 2006 Nov; 163(11):1898-904. Doi: 10.1176/ ajp. 2006.163.11.1898.

5. Berenson A, Carey B. Experts question study on youth suicide rates. New York Times. 2007 Sep 14 [cited 2020 Aug 17]. p 1. Available from: https:// www.nytimes.com/2007/09/14/us/14suicide.htm

6. Jureidini JN, McHenry LB. Conflicted medical journals and the failure of trust. Account Res. 2011 Jan; 18(1):45-54. Doi: 10.1080/08989621.2011.542683.

7. Le Noury J, Nardo JM, Healy D, Jureidini J, Raven M, Tufanaru C, AbiJaoude E. Restoring Study 329: efficacy and harms of paroxetine and imipramine in treatment of major depression in adolescence. BMJ. 2015 Sep 16;16;351: h4320. Doi: 10.1136/bmj.h4320

8. Longo DL, Drazen JM. Data sharing. N Engl J Med. 2016 Jan 21; 374(3): 276-7. doi:10.1056/NEJMe1516564

\section{Be a part of IJME}

IJME invites readers to submit research studies, comments, case studies, reports, reviews, letters, as also poems, short stories, original paintings and photographs of print quality ( both in colour and B/W ) to be considered for publication.

All submitted matter is subject to peer review.

Contributors are neither paid nor charged any fee for published matter. 